\title{
新航海図表について
}

\section{Studies on a New Nautical Nomogram}

\section{高 瀨 義 章 (長大水産学部)}

\begin{abstract}
Adstract
I adovocate here a new spheric triangle on the celestial observation which is denoted by Opposite Meridian Zenith Distance $(S)$, Zenith Distance $(z)$ and Diagonal of a Square consisted of double Declinations and Hour Angle $(H)$ on the Equator. Basing on this idea, the following cosine rule is produced: $\frac{2}{\cos S+\cos z}=\frac{2}{1+\cos H} \times \frac{2}{\cos S+\cos D}$

By the formula, the author has gained a logarithmic nautical table with which nomogram is also drawn.

I believe precisely that Zenith Distance at the moment is in proportion to Hour Angle corresponding to Meridian Zenith Distance $(D)$ which is constant multiple, and that resolution into factors on the rule is very useful for the calculations on the sea, yet theoretical investigation is needed hereafter.
\end{abstract}

\section{緒言}

航海表研究の目的が単に安易さと速度にあるとしたら、航海者が得るとてろよりも寧ろ失うと てろが多いようである。もし安易さと速度が克ち得られたとしても、単一なる観測の結果では到 底満足せられないものであるから、ての意味においては航海表研究の必要性はまてとに疑わし い。然し安易さと速度に精度の向上が加えらるるなら、その研究の価值が全く変つて来る。即ち その要素が確実さにおいて足ら奴ものが多くとも、多数の観測を可能にするてとによつて希求さ れる結果が得られるだろう。

著者が年来、一般に広く使われている航海表：図表等を研究したとてろ、それらの航海表が連 続的な計算に姢何程の便益を与えたかについて研究し、評価の基準を求めることに気付いた。従 つて本研究では、精度を高めると共に計算速度と安易さを增し、且つ連続計算を如何に有利に実 施することが出来るかについて苦心した。

本論において述べる公式は略々以上の三点を満足する結果を示すものと考えられるので、こて に図表の成立する理論の一端を述べ、大方の御批判を乞い将来の研究に資することが出来れば著 者の幸甚てれに過ぎるものはない。

\section{原 理 と作 表}

従来の位置の三角形における cosine rule 
$\cos z=\sin l . \sin d+\cos l \cdot \cos d \cdot \cos H \quad$ から

$$
\begin{cases}l=\text { latitude } & H=\text { hour angle } \\ d=\text { declination } & z=\text { zenith distance }\end{cases}
$$

$\cos \frac{(l+d)+z}{2} \cdot \cos \frac{(l+d)-z}{2}=\cos ^{2} \frac{H}{2} \cdot \cos \frac{(l+d)+(l-d)}{2} \cdot \cos \frac{(l+d)-(l-d)}{2}$

そ変化し、 $\left.\begin{array}{l}l+d=S \\ l-d=D\end{array}\right\}$ とおけば

$$
\cos \frac{S+z}{2} \cdot \cos \frac{S-z}{2}=\cos ^{2} \frac{H}{2} \cdot \cos \frac{S+D}{2} \cdot \cos \frac{S-D}{2}
$$

故に $\frac{2}{\cos S+\cos z}=\frac{2}{1+\cos H} \times \frac{2}{\cos S+\cos D} \cdots \cdots \cdots \cdots$ (1)式 が成立する。

こてで、下図について次の如く定義すれば

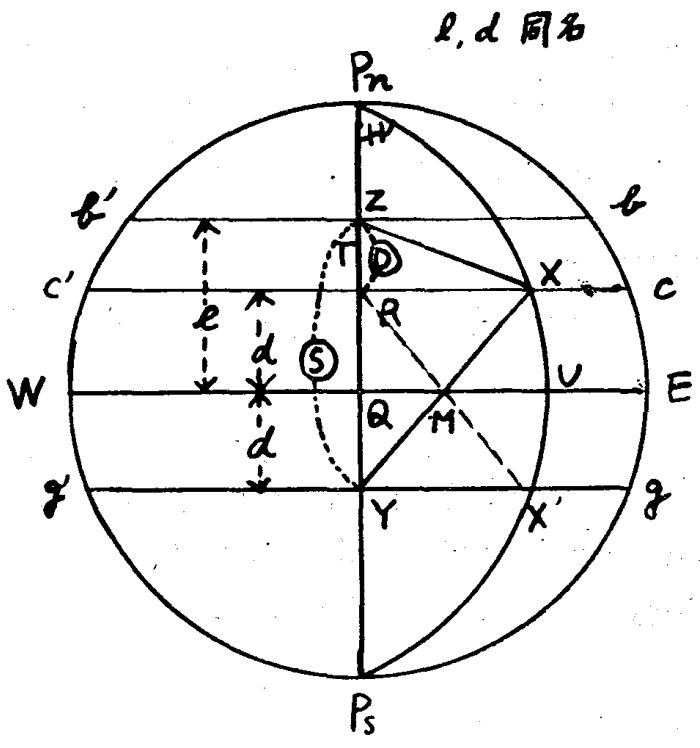

Fig. 1

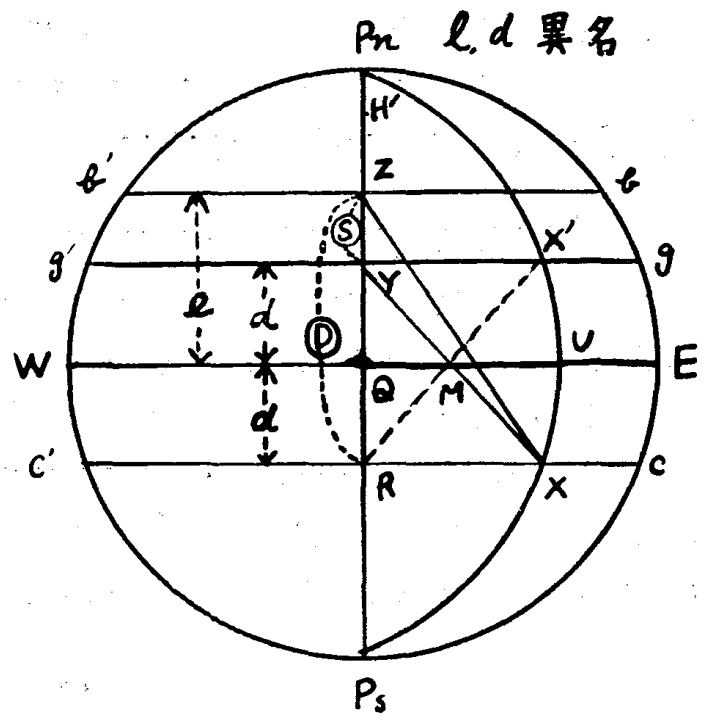

Fig. 2

Pn and Ps.: The pole of the Heaven (or the Earth).

EUQW : The Equator of the Heaven (or the Earth).

$Z \quad:$ The Zenith of an Observer.

$\mathrm{X} \quad$ : The place of a Heavenly Body.

R : The Transfered Point with the same Declination of the Heavenly Body on the Observer's Meridian from $X$ point.

Q : : The Crossed Point of the Observer's Meridian and the Equator.

$\mathrm{X}^{\prime} \quad \therefore$ The Opposite place of the Heavenly Body which is on the adjacent hemi-sphere with the same Declination and Meridian.

$\mathrm{Y}$

: The Transfered Point on the Observer's Meridian from $X^{\prime}$ point, thus $Y$ is the Opposite Point to $R$ point.

ZX

: The Zenith Distance of the Heavenly Body $=(z)$.

ZR : The Meridian Zenith Distance $=(D)$.

ZY

: The opposite Meridian Zenith Distance=(S).

UQ : The Hour Angle on the Equator $=(H)$. 
RXX'Y : The Square being consisted of double Declination and the Hour Angle between the Observer's Meridian and the Meridian of the Heavenly Body.

XY : The Diagonal of the Square $=(F)$.

$\mathrm{bZb}^{\prime} \quad$ : Paralelle of Latitude of the Observer.

$\mathbf{c X c}^{\prime} \quad$ : Paralelle of Declination of the Heavenly Body.

$\mathrm{gX}^{\prime} \mathrm{Yg}^{\prime}$ : Opposite Paralelle of Declination of the Heavenly Body on the adjacent hemi-sphere.

T : The Bisect Point of $(D)$ and $(S)$.

以上の定義により、 $\mathrm{RXX} \mathrm{X}^{\prime} \mathrm{Y}$ における、4箇の直角球面三角形は

$$
\begin{gathered}
\perp \triangle M X U, \equiv \perp \triangle M U X^{\prime} \equiv \perp \Delta M Q Y \equiv \perp \Delta M Q R \text { 従つて } \\
\begin{aligned}
\sec \frac{H}{2} \times \sec d=\sec \frac{F}{2} \quad \therefore \sec ^{2} \frac{H}{2} \times \sec ^{2} d=\sec ^{2} \frac{F}{2} \\
\frac{2}{1+\cos H}=\frac{2}{1+\cos F} \times \frac{1+\cos 2 d}{2} \\
=\frac{2}{1+\cos F} \times \frac{1+\cos (S-D)}{2}
\end{aligned}
\end{gathered}
$$

故に、(1)式は

$$
\frac{2}{\cos S+\cos z}=\frac{2}{1+\cos F} \times \frac{1+\cos (S-D)}{2} \times \frac{2}{\cos S+\cos D}
$$

で表わされるから新しい球面三角形 $Z X Y$ は成立した。従つて (1) 式はその球面三角形によつて 成立したと考えることが出来る。

次に、(1)式を

$\frac{2 \cdot(\cos S+1)}{2 \cdot(\cos S+\cos z)}=\frac{2}{1+\cos H} \times \frac{2 \cdot(\cos S+1)}{2 \cdot(\cos S+\cos D)}$ 亿変形し

対数をとれば

$$
\log \frac{2 \cdot(\cos S+1)}{2 \cdot(\cos S+\cos z)}=\log \frac{2}{1+\cos H}+\log \frac{2 \cdot(\cos S+1)}{2 \cdot(\cos S+\cos D)} \cdots \cdots \cdots \cdots \cdot(2) \text { 式 }
$$

然るに $S$ を定数として $x$ を変数とすれば

$$
\begin{aligned}
\log _{2 \cdot \frac{2 \cdot(\cos S+1)}{2 \cdot(\cos S+\cos x)}} & =\log \frac{2}{\cos S+\cos x}-\log \frac{2}{\cos S+1} \\
& =\log \sec \frac{S+x}{2}+\log \sec \frac{S-x}{2}-2 \log \sec \frac{S}{2} \\
& =\int \frac{\sin x}{\cos S+\cos x} \cdot d x \text { である。 }
\end{aligned}
$$

故に、(2)式は

$$
\int_{0}^{z} \frac{\sin z}{\cos \overline{S+\cos z}} \cdot d x=\int_{0}^{H} \frac{\sin H}{1+\cos H} \cdot d x+\int_{0}^{D} \frac{\sin D}{\cos S+\cos D} \cdot d x \cdots \cdots \cdots \cdots \cdot(3) \text { 式 }
$$

(3)式の中の

$$
\int_{0}^{H} \frac{\sin H}{1+\cos H} \cdot d x \text { は } \int_{0}^{H} \frac{\sin H}{\cos 0^{\circ}+\cos H} \cdot d x \text { と考えるととができるから、(3)式の } 3 \text { 項は }
$$


$S$ と $x$ によるただ一箇の不定積分 $\int \frac{\sin x}{\cos S+\cos x} \cdot d x$ の表である。 即ち、

Table I

\begin{tabular}{|r|rrrrrrrrrr|}
\hline $\begin{array}{r}\text { D. } \\
\text { H.z. }\end{array}$ & $0^{\circ}$ & $10^{\circ}$ & $20^{\circ}$ & $30^{\circ}$ & $40^{\circ}$ & $50^{\circ}$ & $60^{\circ}$ & $70^{\circ}$ & $80^{\circ}$ & $90^{\circ}$ \\
\hline $0^{\circ}$ & 0 & 0 & 0 & 0 & 0 & 0 & 0 & 0 & 0 & 0 \\
$10^{\circ}$ & 33 & 33 & 34 & 36 & 38 & 40 & 14 & 49 & 57 & 67 \\
$20^{\circ}$ & 133 & 134 & 137 & 143 & 151 & 162 & 178 & 200 & 229 & 270 \\
$30^{\circ}$ & 301 & 304 & 311 & 324 & 343 & 370 & 406 & 457 & 526 & 625 \\
$40^{\circ}$ & 540 & 545 & 558 & 582 & 617 & 667 & 736 & 832 & 966 & 1158 \\
$50^{\circ}$ & 855 & 862 & 884 & 923 & 981 & 1065 & 1181 & 1344 & 1576 & 1919 \\
$60^{\circ}$ & 1249 & 1261 & 1295 & 1355 & 1446 & 1576 & 1761 & 2024 & 2411 & 3010 \\
$70^{\circ}$ & 1733 & 1749 & 1799 & 1588 & 2024 & 2222 & 2508 & 2927 & 3572 & 4660 \\
$80^{\circ}$ & 2315 & 2338 & 2411 & 2540 & 2740 & 3037 & 3477 & 4154 & 5288 & 7603 \\
$90^{\circ}$ & 3010 & 3044 & 3148 & 3334 & 3628 & 4075 & 4771 & 5937 & 8299 & $\infty$ \\
\hline
\end{tabular}

$l$ と $d$ が同名ならば $S=l+d 、 D=l+d$ 異名ならば $S=l-d 、 D=l+d \quad S=0^{\circ}$ ならば $\cos 0^{\circ}$ =1より $z=90^{\circ}-a 、 D=H$ 表を兼用される。

nomogram で示せば、Fig. 3 の如く表わすととが出来る。

$x$ は $S=0^{\circ}$ のとき $H$ と置換し、 $S$ が $0^{\circ} \rightarrow 90^{\circ}$ のとき、 $D$ 又は $z=\left(90^{\circ}-a\right)$ としても置換 し得る。

故に(3)式は、頂距の積分值が子午線項距の積分值を比例常数として、時角の積分值に正此例し ているととを意味する。

(3)式の各項の微分係数は $\frac{\sin x}{\cos S+\cos x}$ で表わされるが、 $x$ を定数として $S$ を変数とした $\frac{\sin S}{\cos S+\cos x}$ も存在する。故にそれぞれの微分係数を

$$
\begin{array}{ll}
\frac{\sin z}{\cos S+\cos z} \cdot d x, M=\Delta z & \frac{\sin H}{1+\cos H} \cdot d x . M=\Delta H \\
\frac{\sin D}{\cos S+\cos D} \cdot d x . M=\Delta D & \frac{\sin S}{\cos S+\cos D} \cdot d x . M=\Delta S_{1} \\
& \frac{\sin S}{\cos S+\cos z} \cdot d x . M=\Delta S_{2}
\end{array}
$$

以上の如く命名すれば

$$
Z=\text { Azimuth として }
$$

$$
\left.\begin{array}{l}
\frac{\Delta H \times \sec l}{\Delta z}=\sin Z \cdots \cdots \cdots \cdots \cdots \cdots \cdots \cdots(4) \text { 式 } \\
\frac{\Delta D-\left(\Delta S_{2}-\Delta S_{1}\right)}{\Delta z}=\cos Z \cdots \cdots \cdots \cdots \cdots(5) \text { 式 }
\end{array}\right\} \text { 関係式が得られる。 }
$$

（文献参照 高瀬義章、微分方程式による新航海表の研究）

(4)式、(5)式の何れかを使つて方位角を求めるてとは、(3)式の微分係数の関係であつて別の公式 を用いるととではない。従つて表の量の節約と計算の手数を省くことに役立つている。 


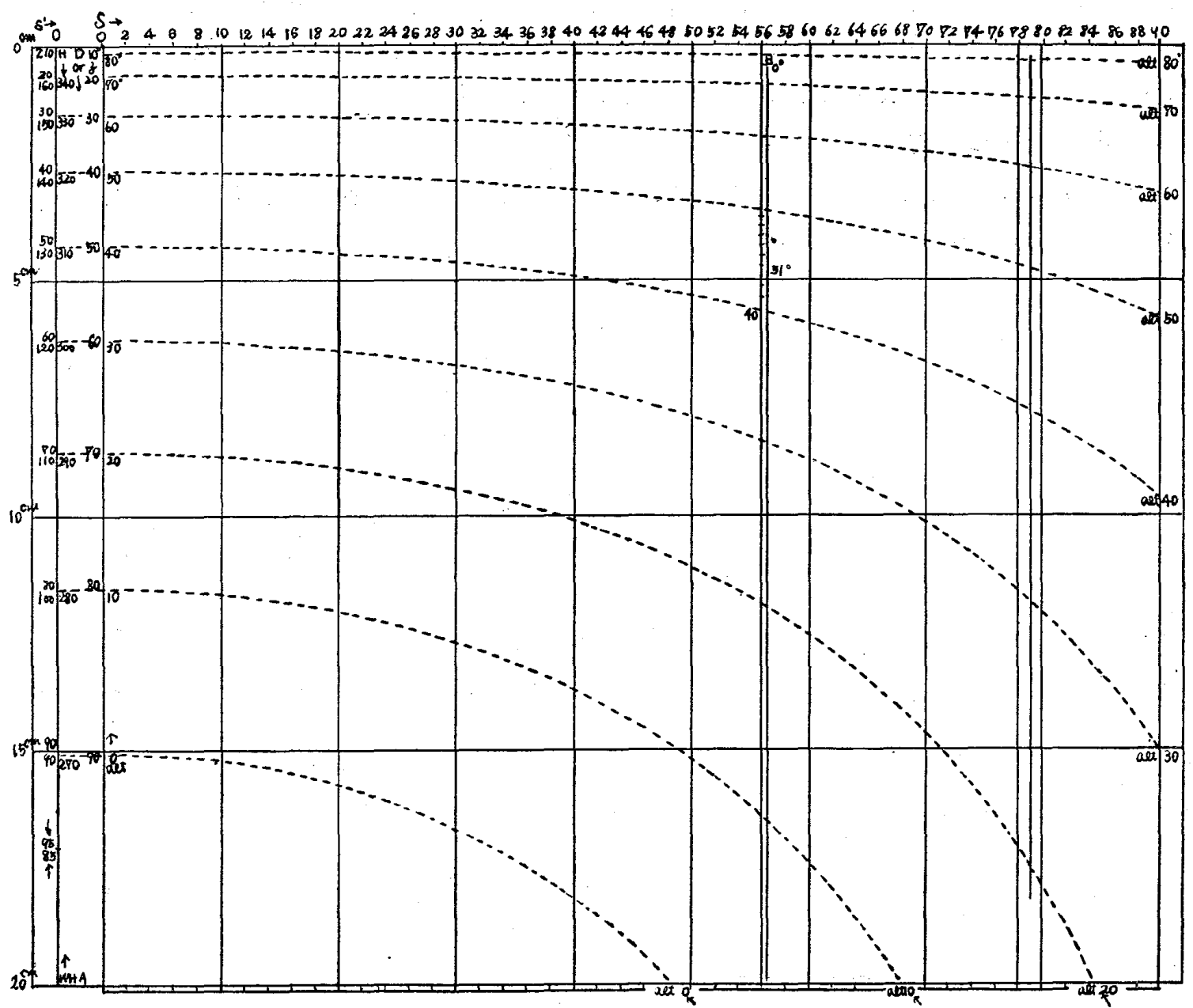

Fig. 3

\section{計 算 例 と図 表 概 説}

I. Fig. 3 そついて

A. 高度計算法

$$
\text { 例 } \begin{array}{ccc}
1 & & \\
H & 51^{\circ}-00^{\prime} & E \\
d & 20-20 & N \\
l & 35-40 & N \\
l+d=S & 56-00 & \\
l+d=D & 15-20 \\
l-d=D & \text { alt }=43^{\circ}-00^{\prime}
\end{array}
$$

B. 方位計算法

$$
\begin{array}{cc}
a & 43^{\circ}-00^{\prime} \\
l & 35-40 N \\
a+l=S^{\prime} & 78-40 N \\
a-l=D^{\prime} & 7-20 \\
d & 20-20 \\
Z=S & 85^{\circ} E
\end{array}
$$

異名である。
左端 $H$ 尺は $S 0^{\circ}$ の尺と全く等しい。

i ） $H$ 尺基点 $0^{\circ}$ を $S 6^{\circ}$ 線上において $D=15^{\circ}-20^{\prime}$ 亿当て る。

ii ） $H$ 尺上 $51^{\circ}-00^{\prime}$ に進み、その目盛に当る $S$ 尺上の目盛を 下方より読めば、高度 $43^{\circ}-00^{\prime}$ が得られる。

方位角計算では $H$ 尺は $Z$ 尺と変る。

i ） $Z$ 尺基点 $0^{\circ} S^{\prime}$ を 尺 $79^{\circ}$ 上で $D^{\prime}=7^{\circ}-20^{\prime}$ 垱てる。

ii ）その $S^{\prime}$ 尺上に沿つて下から読んだ alt の度数を $d=20^{\circ}-$ $20^{\prime}$ 亿置き換えて、それ能る $Z$ 尺の度数在読めぼ方位角であ る。但し上方から読んだ度数は、緯度と同名下から読めば緯度と

Fig. 3 の図表は $200 \mathrm{~mm} \times 225 \mathrm{~mm}$ であるので $0.1 \mathrm{~mm}$ の精度としても㸚を 4 桁で容れてい 
るに過ぎないから、高度、方位角とも普通 $00^{\circ} 5$ 範囲と思われる。この方式で $600 \mathrm{~mm} \times 450 \mathrm{~mm}$ 、 或は $1.0 \mathrm{~m} \times .45 \mathrm{~m}$ と延長してもその精度は $0.0^{\circ} 1$ 位のものと考元られる。なほての方式隹う図 表は、S. $S^{\prime}$ 及 $D . D^{\prime}$ が余り大きくなると計算が不能になる矢点がある。

II. Fig. 4 困表について

Fig. 4 に示してある図表は Fig. 3 の図表の一部分を 200 倍に引伸した、3枚の困表が重ね合 わされているものとして理解されるッ

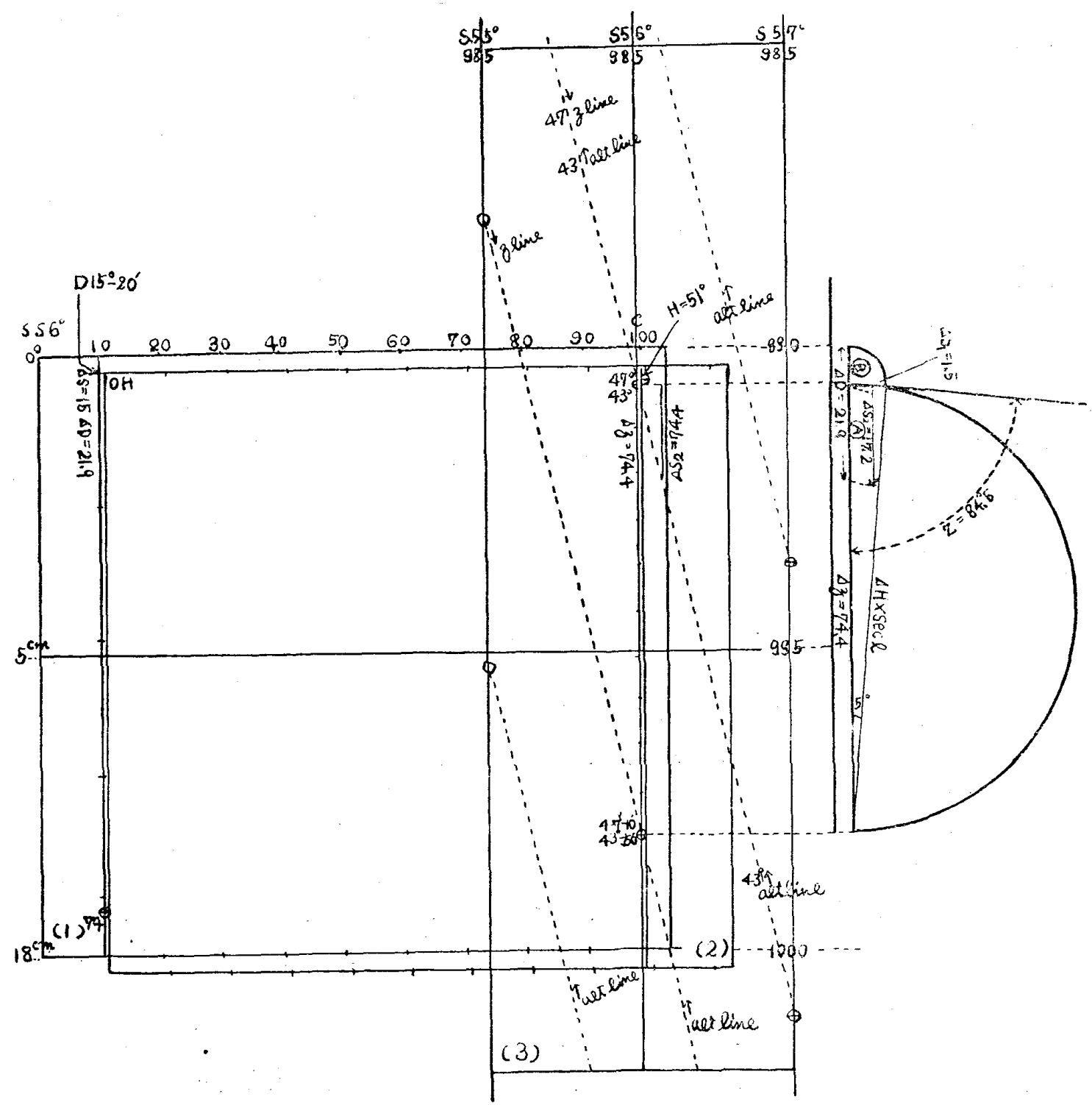

Fig. 4

即ち、

(1) $S 56^{\circ} 10 \mathrm{~cm}$ の長さの詨数尺が $1 \mathrm{~mm}$ 間隔で左から、名に並んでいる。

(2) $S 56^{\circ}$ を中心にして左右に $2.5 \mathrm{~cm}$ を隔てて、S $55^{\circ} 、 S 57^{\circ}$ の対数線数が並んで上下に 延び、S $56^{\circ}$ の 990 の対数値が○印、C点に置かれている。

(3)（1)の尺に準じた尺 $H$ 図表である。

(4) 高度計算法

例 3 (例 1 の要素洞じ) 


$$
\begin{array}{cl}
H & 51^{\circ}-00^{\prime} \\
l & 20-20^{\prime} N \\
\boldsymbol{d} & 35-40^{\prime} N \\
l+d=S & 56-00 \\
l-d=D & 15-20 \\
\text { C. } \text { alt }=43^{\circ}-\mathrm{C}-0^{\prime} 1
\end{array}
$$

(1)の図表上に(3)の図表を重ねて

a ）(1)の図表上 $D=15^{\circ}-20^{\prime}$ に(3)の基点 $H=0^{\circ}$ を合せる。

b ）(3)図表上右方 $H=51^{\circ}$ を読み

c）その目盛を、下にある(1)の図上に当つている目盛で読み換え れば alt $=43^{\circ}-00.1$ が得られる。

(5) 方位計算法

図表は全然動かさないで、上揭の高度計算法を行つた時の a ) 及 c ）の場合その傍に表わされ ている微分係数を計算すればよい。

即ち、例 4

$$
\begin{aligned}
& \Delta S_{1} \quad 1.5(\sim) \quad \Delta D 21.9 \quad \text { d ） a ) のとき微分係数 } \Delta S_{1} \text { と } \Delta D \text { を読む。 }
\end{aligned}
$$

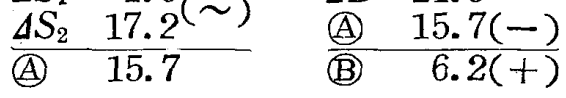

$$
\begin{aligned}
& \Delta z \quad 74.4 \text { 換した数である)を読み、左記の計算例の通り } \\
& \text { e ) c) のとき } \Delta S_{2} \text { と } \Delta z(\Delta z \text { と } \Delta D \text { は名前だけ置 } \\
& Z S 85 .^{\circ} 1 E \\
& \Delta S_{2}-\Delta S_{1}=\text { (A) } \Delta D-(A)=\text { (B) と(B)を求め、 } \Delta z \text { と(B) }
\end{aligned}
$$

を以て右方に揭げた様に作図すれば、方位角及位置の線並行線が得られる。

即ち $\frac{(B)}{\Delta z}=\cos Z$ である。

附記

1 ) 本論では到底論及出来ないが、指数曲線図表を使つて、微分係数の比を百分比に直して方 位角を計出し、叉数表の挿入計算を簡単にする図表が立案されている。

2 ）なほ四表中重的合わされている(2)の図表は $\Delta D$ と $\Delta S$ が $10^{\prime}$ 間隔の線数の差よりその両 側の平均值にして測定出来るものである。

\section{結 論}

（I） この航海図表は尺度の小なるものでは仮定位置を使用するかに見えるが $さ 1^{\circ}$ について $50 \mathrm{~cm} \times 45 \mathrm{~cm}$ なる面積の図表とすれば、推定位置使用が可能となるととは Fig. 4 により看取さ れる。即ち精度 0.5 古目標にすることはさほど困難ではないといえる。図表の大部分において 0.1 の精度は確実であると思われる。

（2）連続計算が簡単容易であるととは高度が不正確な昜合、及特に高い精度を必要とする場合 に利益を増すととは確実である。

(3) この理論は子午線頂距を計出することが出来るから、新しい緯度計算法が成立する。

（4）微分係数を使つて方位角、又は位置の線を作図するてとは原始函数を使う計算と何ら差異 がないものである。但し桁数を等しくしてのてと。

本論によつて、以上の如く結論するてとが出来るとすれば、航海実用計算に応用して有効であ ると確信される。ただし図婊は結局理論の全体を尽すととは出来ない。その使用頻度の高いとと ろを満たすに過ざない。つまり図表は数表を基礎的なものとして、その理論の実用価值を高める ととに役立つものと考えるべきである。

\section{参考文 献}

1) 秋吉利雄 : 航海天文学の研究 (1952)

2）高瀬義章：微分方程式による新航海表の研究、長崎大学水産学部研究報告 No. 5. P. P. 41 52. 